\title{
Research on the Identification of the Core Competence of Pharmaceutical Logistics Enterprises Guided by Service
}

\author{
Bing $\mathrm{Li}^{1}$, Xinyu Yang ${ }^{1, \mathrm{a}, *}$ \\ ${ }^{1}$ School of Management Engineering, Zhengzhou University, Zhengzhou 450001, China \\ ${ }^{a}$ 1934378936@qq.com \\ *Corresponding author
}

Keywords: pharmaceutical enterprises; third-party logistics; core competencies; grey correlation degree; recognition analysis

\begin{abstract}
With the rapid development of science and technology and acceleration of economic globalization, many companies begin outsourcing logistics, release time and attach attention to the development of the main business enterprises, which will provide favorable conditions for the development of logistics enterprises, greatly promote the development of the third party logistics. But the pharmaceutical logistics enterprises did not in a good position in the fierce competition, the reason lies in the lack of core competitiveness. So the medical logistics enterprise must adjust the strategic direction of development, development of the core competitiveness of enterprises on the basis of positioning difference from other enterprises, in order to obtain better development. This paper analyzes the current situation of the development of pharmaceutical logistics enterprises in China, studies the effect of core competitiveness of pharmaceutical logistics enterprises by using the grey correlation evaluation method as well as the current situation of logistics development. It finally puts forward some references for the future development of the pharmaceutical logistics enterprises.
\end{abstract}

\section{INTRODUCTION}

Selection of medical logistics research has important theoretical significance and practical significance. Based on the related data and literature review, research, and expert analysis, in-depth study of the existing mode of China's pharmaceutical logistics and problems, and identification of the core competitiveness of pharmaceutical logistics enterprises using grey correlation degree the evaluation method, and enrich the theory of medical logistics; through the study of the third party logistics enterprise, understand the development status of the third party logistics enterprises, to identify its core competitiveness, combined with the relevant enterprises, to put forward feasible suggestions to promote the development of pharmaceutical logistics.

\section{LITERATURE REVIEW}

In recent years, many researches on core competitiveness have been carried out. At home, Zeng jinming [1] puts forward feasible Suggestions for the improvement of core competitiveness of third-party logistics enterprises in China by using fuzzy comprehensive evaluation methods for the core competitiveness of third-party logistics enterprises. Du Yi [2] in studies of the third party logistics enterprise core competitive ability is proposed in, using the SWOT analysis of the factors influencing the core competence of weights, for Suzhou third party logistics enterprise core competitive power evaluation and ascension offers certain theoretical reference value. Zhang Haiyan [3] puts forward how to improve the core competitiveness of pharmaceutical logistics enterprises. Tang Youming etc [4] widely draw lessons from foreign research results, through the research on the characteristics of the third party logistics enterprise, this paper puts forward the index system of the third party logistics enterprise to build, with fuzzy analysis method to the development of third party logistics enterprise are proposed. LuanRui [5] think competition including logistics competition between enterprises, the article through to the third party logistics core competitiveness evaluation, analysis, put forward to help improve the third party logistics enterprise core competitive power of Liaoning province guidance advice.

Abroad, Gary Holmes, Nick Hooper [6] in the "core competitiveness and education" put forward in order to better adapt to the development of education, the core competitive power is applied to the British education, instructional Suggestions are also given. Shi-rong HU, Ding-xuan Huang [7] analyzed the essence of existing core competitiveness in "the recognition of the essence of core competitiveness", studied how to improve the core competitiveness of enterprises, and gave guidance advice. The Qingdong LI [8] in the comprehensive evaluation and application of "core competence" pointed out that the core competitiveness is the key to business success factors, and build the evaluation index system, the fuzzy comprehensive evaluation model to evaluate enterprise's core competitiveness, put forward opinions. Chich Jen Shieh [9] in "management innovation, the relationship between corporate culture and corporate core competitiveness" in put forward the management innovation and corporate culture are the core competitiveness of enterprises have a certain influence, and accordingly put forward the corresponding suggestion.

Throughout the literature of the scholars at home and 
abroad, although the core competitiveness of pharmaceutical logistics enterprises conducted many studies, but there is no a unified standard to the medicine of the third party logistics enterprise core competitive ability category definition; In addition, the research on the evaluation of third-party pharmaceutical logistics enterprises is not perfect, and the theoretical basis is insufficient, and there are still many problems worth studying.

\section{PROBLEM DESCRIPTION AND ANALYSIS}

\subsection{Problem description}

With the rapid development of economy, logistics industry more professional, so the development of the third party logistics has become a kind of characteristics of the logistics industry is much more professional, in our country, the development of pharmaceutical logistics is not a long time, so there are many problems:

(1) Institutional barriers [10]. In China, the development of pharmaceutical logistics is slow in part because of institutional barriers, such as local protection and administrative division of pharmaceutical market. Because of the market segmentation, it is easy to lead to "large and small whole" pharmaceutical logistics enterprises.

(2) Low capacity of enterprise supply chain and high logistics cost. Medicine of the third party logistics enterprise supply chain is refers to the surrounding medicine core enterprise, from raw materials procurement, it made medicines, finally to its sales to the hospital and consumers in the hands of integrating suppliers, distributors, retailers until a function nets chain mode of consumers. Since most people are less aware of pharmaceutical logistics, enterprises pay more attention to market share and ignore the cooperative development of pharmaceutical logistics industry, so the supply chain capacity is low.

(3) Logistics information degree is low. Logistics information platform is to point to include the owner, supplier, transportation, bank, the platform of logistics information system, such as for some of the logistics demand of enterprises, government departments to provide professional information platform of logistics information. But at present, China's logistics information platform is not perfect, so it cannot effectively use the platform to deliver logistics information, and the speed of logistics is slow.

In conclusion, the core competitiveness of China's pharmaceutical logistics enterprises is not clear and its properties are not obvious.

\subsection{Problem analysis}

The core competitiveness of pharmaceutical logistics enterprises is the key to the pharmaceutical logistics enterprises to maintain competitive advantage, and is the fundamental to achieve maximum customer value. But because the influence factors of medical logistics enterprise's core competitiveness, and many different influence, to determine the main factors, so the core competitiveness of pharmaceutical logistics enterprises need to analyze, determine the main influencing factors of the core competitiveness of enterprises, the enterprise resources and technology can be put into key areas, play the maximum value.

\section{RESEARCH ON CORE COMPETITIVENESS OF PHARMACEUTICAL LOGISTICS ENTERPRISES}

\subsection{Selection of evaluation methods for core competence of medical logistics}

At present there are several methods of evaluation of the pharmaceutical logistics enterprise's core competitiveness, the most widely used is the fuzzy comprehensive evaluation method, followed by data envelopment analysis and grey relational evaluation method [11], this method also includes principal component analysis, factor analysis, and neural network evaluation method, each method is different, but the gray correlation analysis method can well describe the fuzzy evaluation index of the core competitiveness of enterprises, do not need to have the typical distribution and number of the sample volume are not required. In order to provide the basis for cultivating and promoting the core competence of enterprises, this paper chooses the grey relational grade evaluation method to study the core competence of pharmaceutical logistics enterprises.

\subsection{Grey relational grade evaluation model of core competitiveness of third party logistics enterprises}

To design the evaluation dimension of core competence, we can start from the characteristics of core competence, and extract the main factors to evaluate the dimensions. This paper selects two dimensions, profitability and inimitability as evaluation dimensions, can determine a two-dimensional coordinate evaluation, the core competitiveness of each enterprise occupies a unique position in the coordinate system, compare the different core competitiveness of enterprises, will be able to identify the advantages and disadvantages.

In this paper, the grey relational grade evaluation method of the core competence of pharmaceutical logistics enterprises includes the following steps [12]:

(1) Establish evaluation index system [13]. The following rules include the scientific principle, the system optimization principle, the general comparability principle, the pragmatic principle and the goal oriented principle. For different industry indicators are different, this paper on the back of the hand, and builds the evaluation index system of a medical logistics enterprise's core competitiveness, and based on this, the pharmaceutical logistics enterprises in the evaluation of core competence.

(2) Get raw data and standardize it. The collected data should be as accurate and detailed as possible and represent the latest development direction of the enterprise. In order to ensure the reliability of the result, it is necessary to standardize the original index value and make the data between $0-1$ for processing and analysis [13]. The different user questionnaire, using the principle of fuzzy statistics, the recovery of useful data in the questionnaire according to the number of evaluation 
criteria of membership sum divided by the investigation, to quantify the qualitative index. The specific process is as follows:

Among them, $V$ indicates grade intensity. $V=\{V 1$ (strong), $V_{2}$ (stronger), $V_{3}$ (general), $V_{4}$ (weaker), $V_{5}$ (weak) , And $N_{1}+N_{2}+N_{3}+N_{4}+N_{5}=N$. The total number of $N$ surveyed is the membership vector of qualitative index. $R_{i}=\left(N_{1} / N, N_{2} / N, N_{3} / N, N_{4} / N, N_{5} / N\right)$. Set $B=\left(B_{1}\right.$, $\left.B_{2}, B_{3}, B_{4}, B_{5}\right)=(0.9,0.7,0.5,0.3,0.1), B_{j}$ represents the scale corresponding to the $\mathrm{j}$ level evaluation index. By calculating the $R_{i} * B^{T}$, the membership vector of the fuzzy variable can be transformed into a quantized value of an interval of [0-1], which quantifies the qualitative index. According to the nature of the evaluation index, which can be divided into four categories, including the better the efficiency index, the smaller the better the cost indexes, an optimum value of moderate type index and the index on an interval optimal interval index, so the function of four kinds of different specifications the type of index dimensionless processing.

Table 1 fuzzy statistical results table of qualitative indicators

\begin{tabular}{cccccc}
\hline Grade & $\mathrm{V}_{1}$ & $\mathrm{~V}_{2}$ & $\mathrm{~V}_{3}$ & $\mathrm{~V}_{4}$ & $\mathrm{~V}_{5}$ \\
\hline $\begin{array}{c}\text { A person who } \\
\text { considers the rating } \\
\text { to be of this rank }\end{array}$ & $\mathrm{N}_{1}$ & $\mathrm{~N}_{2}$ & $\mathrm{~N}_{3}$ & $\mathrm{~N}_{4}$ & $\mathrm{~N}_{5}$ \\
\hline $\begin{array}{c}\text { Membership } \\
\text { degree }\end{array}$ & $\mathrm{N}_{1} / \mathrm{N}$ & $\mathrm{N}_{2} / \mathrm{N}$ & $\mathrm{N}_{3} / \mathrm{N}$ & $\mathrm{N}_{4} / \mathrm{N}$ & $\mathrm{N}_{5} / \mathrm{N}$ \\
\hline
\end{tabular}

Benefit index: $y_{i}=\frac{x_{i}-x_{\min }}{x_{\max }-x_{\min }}$;
Cost index: $\quad y_{i}=\frac{x_{\max }-x_{i}}{x_{\max }-x_{\min }}$;

Moderate index: $y_{i}=\frac{1}{1+\left|x_{0}-x_{i}\right|}$;

Interval index:

$$
y_{i}=\left\{\begin{array}{l}
1-\frac{x_{1}-x_{i}}{\max \left(x_{1}-x_{\min }, x_{\max }-x_{2}\right)}, \\
x_{i}<x_{1} \\
1-\frac{x_{i}-x_{2}}{\max \left(x_{1}-x_{\min }, x_{\max }-x_{2}\right)}, \\
x_{i}>x_{2}>1, x_{1}<x_{i}>x_{2}
\end{array}\right.
$$

In the formula, the best value of the actual I index representing the $x_{i}, x_{0}$ value and moderate index; $\left[x_{1}, x_{2}\right]$ represents the ideal interval index; $x$ and $I$ respectively represent the index of maximum and minimum sample value; $y_{i}$ is no standard function of the dimensionless index.

(3) Calculate. Usually from the profitability and not two aspects of imitative evaluation of core competitiveness of the size of the marked results, in the same plane coordinates.

(4) Synthesis of core competence.

According to the two dimensions, the calculated results of core competence are classified, and the grey relational grade of the enterprise is calculated respectively. Results of enterprise core competence are drawn as icon and analyzed

Table 2 core competence constitutes the factor evaluation index

\begin{tabular}{ccc}
\hline Elements of core competence & dimension & evaluating indicator \\
\hline Human resource capability & Profitability & Total labor productivity、 Per capita profit margin \\
\cline { 2 - 3 } & Non imitation & Staff skill level、 Team learning ability \\
\hline Market development capability & Profitability & $\begin{array}{c}\text { Principal operating income、 Main operating } \\
\text { income growth rate }\end{array}$ \\
\cline { 2 - 3 } & Non imitation & $\begin{array}{c}\text { Brand awareness Brand reputation、 Brand } \\
\text { history } \text { marketing network }\end{array}$ \\
\hline $\begin{array}{c}\text { competence to intellectual } \\
\text { property right claims }\end{array}$ & Profitability & $\begin{array}{c}\text { Core product sales revenue Share of new product } \\
\text { output value }\end{array}$ \\
\cline { 2 - 3 } & Non imitation & Patent ownership v Product uniqueness \\
\hline
\end{tabular}

\section{CASE STUDY}

In this paper, four companies are selected for the development of cold chain logistics. In order to protect the privacy of enterprises, four enterprises are replaced by A, B, C and D. Company A is a famous old pharmaceutical shop in China. B enterprise is a sino-foreign joint venture, $\mathrm{C}$ is a high-tech group enterprise, and D is a joint-stock enterprise [15].

The method of grey relational analysis for the core competence of pharmaceutical logistics enterprises is as follows:

(1) Establishing evaluation index system. As the enterprises in the same industry study, the policy environment of the four companies is similar, so the impact of the national policy on the core competitiveness of enterprises is not considered, and the index evaluation system is established as follows:

(2) Data acquisition

Get the raw data for the following four companies by searching through the Internet, looking at the papers and the company's annual reports.

(3) Grey relational analysis and spatial location of the core competitiveness elements

This paper takes the profitability dimensions of organizational coordination ability as an example to illustrate the grey correlation degree of the dimensions of the core competitiveness of each company. Process is as follows:

1) Determine the optimal index set $\left(F^{*}\right)$

Set $F^{*}=\left\{j_{1}{ }^{*}, j_{2}{ }^{*}, \ldots, j_{n}{ }^{*}\right\}$, in the formula, $j_{k}{ }^{*}$ 
$(k=1,2, \ldots, n)$ represent the best value of the $\mathrm{K}$ index. This optimal value can be either the optimal value or the optimal value in the ideal state, and the optimal value of each enterprise is used in the study.

After selecting the optimal index set, the matrix $D$ can be constructed

$$
D=\left[\begin{array}{cccc}
j_{1}^{*} & j_{2}^{*} & \cdots & j_{n}^{*} \\
j_{1}^{1} & j_{2}^{1} & \cdots & j_{n}^{1} \\
\vdots & \vdots & & \vdots \\
j_{1}^{m} & j_{2}^{m} & \cdots & j_{n}^{m}
\end{array}\right]=\left[\begin{array}{cccc}
15.2 & 25.7 & 0.9 & 215 \\
12.6 & 25.7 & 0.7 & 119.8 \\
2.7 & 8.4 & 0.7 & 215 \\
12.7 & 14.6 & 0.9 & 32.7 \\
15.2 & 7.3 & 0.9 & 105.6
\end{array}\right] \text { In the }
$$

formula, $j_{k}{ }^{i}$ stands for the initial value of the first $\mathrm{K}$ index in the $I$ enterprise.

2) Standard treatment of index value

The original index value is standardized, and the standardized value is $C_{k}{ }^{i}$. Then the $D \quad C$ matrix

$$
C=\left[\begin{array}{cccc}
C_{1}^{*} & C_{2}^{*} & \cdots & C_{n}^{*} \\
C_{1}^{1} & C_{2}^{1} & \cdots & C_{n}^{1} \\
\vdots & \vdots & & \vdots \\
C_{1}^{m} & C_{2}^{m} & \cdots & C_{n}^{m}
\end{array}\right]=\left[\begin{array}{cccc}
1 & 1 & 0.9 & 1 \\
0.792 & 1 & 0.7 & 0.4778 \\
0 & 0.0598 & 0.7 & 1 \\
0.8 & 0.3967 & 0.9 & 0 \\
1 & 0 & 0.9 & 0.3999
\end{array}\right]
$$

3) Calculate the comprehensive evaluation results

According to the theory of grey system, $\left\{C^{*}\right\}=\left\{C_{1}{ }^{*}, C_{2}{ }^{*}, \ldots, C_{n}{ }^{*}\right\}$ As reference sequence, and other data are $\{C\}=\left\{C_{1}{ }^{i}, C_{2}{ }^{i}, \ldots C_{n}{ }^{i}\right\}$ Compared with correlation analysis method, obtained the delta I correlation coefficient I of the enterprise $K$ index and the $\mathrm{K}$ index of the optimal $\delta_{i}(k)$,

$$
=\frac{\min _{i} \min _{k}\left|C_{k}^{*}-C_{k}^{i}\right|+\rho \max _{i} \max _{k}\left|C_{k}^{*}-C_{k}^{i}\right|}{\left|C_{k}^{*}-C_{k}^{i}\right|+\rho \max _{i} \max _{k}\left|C_{k}^{*}-C_{k}^{i}\right|}
$$

In the formula, $\rho \in[0,1]$, General $\rho=0.5$.

The judgment matrix of each index can be obtained by $\delta_{i}(k)$

$$
E=\left[\begin{array}{cccc}
\delta_{1}(1) & \delta_{1}(2) & \cdots & \delta_{1}(n) \\
\delta_{2}(1) & \delta_{2}(2) & \cdots & \delta_{2}(n) \\
\vdots & \vdots & & \vdots \\
\delta_{m}(1) & \delta_{m}(2) & \cdots & \delta_{m}(n)
\end{array}\right]=\left[\begin{array}{cccc}
1 & 1.6932 & 1.0160 & 0.6179 \\
0.3908 & 0.4096 & 1.0160 & 1.6932 \\
1.0160 & 0.5624 & 1.6932 & 0.3908 \\
1.6932 & 0.3908 & 1.6932 & 0.5644
\end{array}\right]
$$

The grey comprehensive evaluation model is $R=E^{*} W$, evaluation criteria, $W=\left(w_{1}, w_{2}, \ldots, w_{n}\right)^{\mathrm{T}}$ Weight allocation vectors for $\mathrm{n}$

$$
R=E * W=\left[\begin{array}{cccc}
1 & 1.6932 & 1.0160 & 0.6179 \\
0.3908 & 0.4096 & 1.0160 & 1.6932 \\
1.0160 & 0.5624 & 1.6932 & 0.3908 \\
1.6932 & 0.3908 & 1.6932 & 0.5644
\end{array}\right]=\left[\begin{array}{c}
0.25 \\
0.25 \\
0.25 \\
0.25
\end{array}\right]=\left[\begin{array}{c}
1.0 \\
0.8774 \\
0.9156 \\
0.854
\end{array}\right]
$$

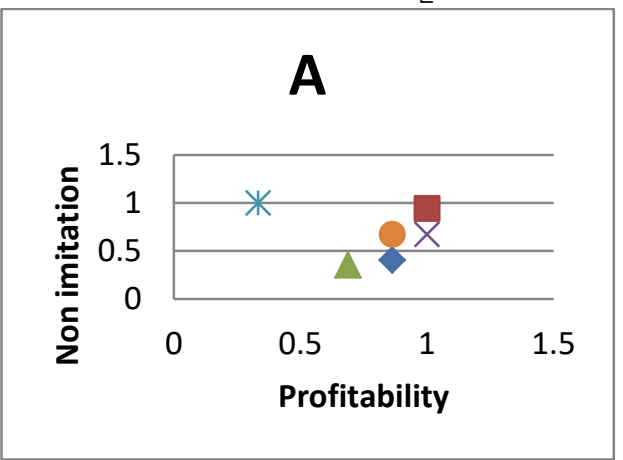

Figure $12 \mathrm{D}$ profiles of $\mathrm{A}$

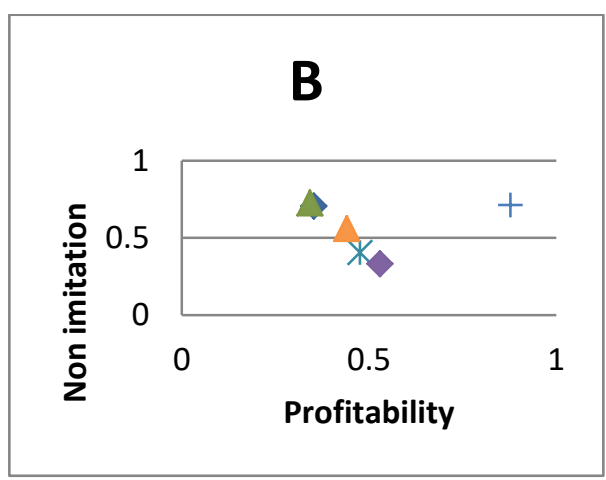

Figure 2 2D profiles of B

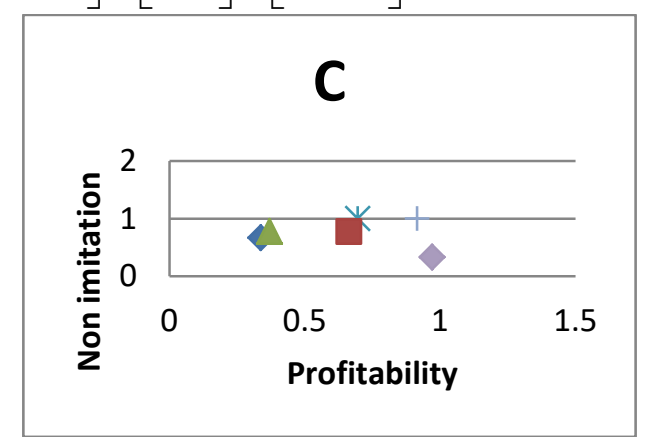

Figure $32 \mathrm{D}$ profiles of $\mathrm{C}$

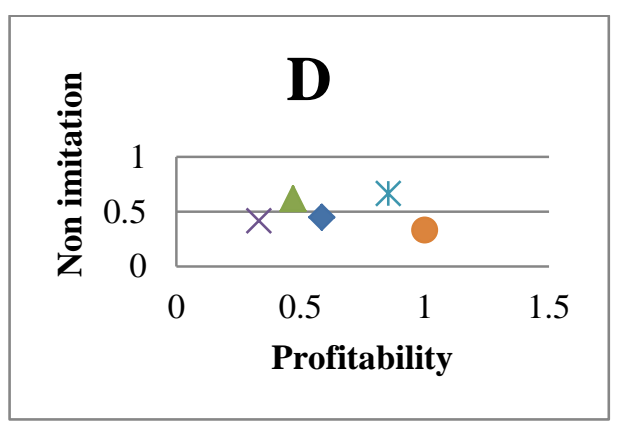

Figure 4 2D profiles of D

The following will be the core competitiveness of the whole distribution of four company marked were compared in the same coordinate diagram, as shown in 
figure A: can be seen, the company in terms of profitability or inimitability terms than the other two companies, including A company most profitable, C company inimitability the strongest.

However, to make sure which enterprise has the strongest core competitiveness, it is possible to evaluate all the data by grey relational grade. The order of degree of correlation is the order of the core competence of enterprise. According to this principle, we can find the order of the core competitiveness of the four companies, as shown in the table:

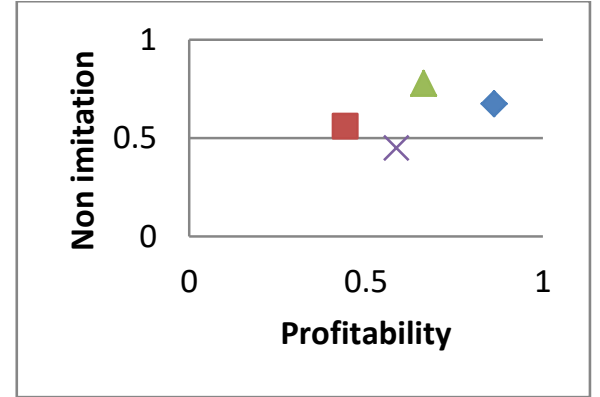

Figure 5 four company core competitiveness two-dimensional distribution map

Sort out the size of the core competencies of the four companies:

Table 3 ranking of core competitiveness of four companies

\begin{tabular}{lllll}
\hline & A & B & C & D \\
\hline Size & 0.7666 & 0.5549 & 0.7108 & 0.5564 \\
\hline sort & 1 & 4 & 2 & 3 \\
\hline
\end{tabular}

As can be seen from the table, A company's core competitiveness is strongest, followed by $\mathrm{C}$, followed by $\mathrm{D}$, B's core competitiveness is weakest. As can be seen from Figure 2, the most important factor affecting the core competitiveness is market development capability.

\section{THE STRATEGY TO ENHANCE THE CORE COMPETITIVENESS OF FORM "INTERNET PLUS"}

Through the analysis of the factors affecting the pharmaceutical logistics enterprise's core competitiveness, combined with the current develop of "Internet plus", put forward the strategy to enhance the core competitiveness of:

(1) According to the government's policy, health care reform is carried out. The development of "Internet plus medicine", promote the transformation and upgrading of traditional medicine industry. The merger and reorganization of pharmaceutical enterprises is an important way to improve the core competitiveness of pharmaceutical logistics enterprises.

(2) Improve the supply chain of the third party logistics, and supply the chain as a value-added chain covering the whole process of product movement.

To coordinate all the pharmaceutical logistics enterprises can through information sharing, improve operational efficiency and measures to build partnerships and trust mechanism to achieve the supply chain, and reduce operating costs, improve operational efficiency.

In short, the supply chain logistics system not only affects the supply chain system of customer service, will also affect the supply chain process time and total cost, therefore, in the supply chain logistics management, should balance the level of customer service and cost targets, make full use of information technology and partner resources, transportation, supply chain management inventory, to realize the optimization of supply chain logistics.

(3) Strengthen the existing logistics equipment, improve the logistics management style, and improve the logistics service ability.

The medicine of third party logistics enterprises by systematic and scientific practice on logistics to design, so as to strengthen the management of logistics in the procurement, production, distribution, distribution and other aspects of the. At the same time, according to the particularity of medicinal products, update the storage and transportation equipment of drugs, improve the storage and transportation capacity of logistics equipment and storage and transportation efficiency, and improve the overall level of logistics services.

\section{ACKNOWLEDGEMENTS}

This research is supported by National Natural Science Foundation of China (Grant No. U1604150), Humanities \& Social Sciences Research Foundation of Ministry of Education of China (Grant No. 15YJC630148), Distinguished Young Teacher Development Foundation of Zhengzhou University (1421326092), and Key Research Foundation of University Education in Henan province (17A520058). The authors would like to thank the editors and anonymous referees for their careful and fruitful comments to improve the quality of this paper.

\section{REFERENCES}

[1] Guo Xuedao. The analysis of the core competitiveness of the third-party logistics enterprises in China [J]. social vision [2] Urban Ljungquist. Going Practical on the Core Competence Concept: On Links, Levels, Time and Context. Knowledge and Process Management [J].2013, 20(4):223-231

[3] Bo Zou. Capital Market and Enterprise Core Competitiveness Interaction Mechanism-Based on the Case of Kang mei Pharmaceutical Co., Ltd. Modern Economy [J].2015,6:465-472

[4] Wang Wei. Study on the core competence of third party logistics [J]. Journal of Chongqing University of Science and Technology, 2011 (4): 121-123

[5] Dai Jingjing. Analysis and cultivation of the core competence of third party logistics enterprises in China. [J]. logistics technology, 2014,33 (12): 183-

[6] Xu Yaqiong. Analysis of the cultivation and promotion of the core competitiveness of the third party logistics enterprises [J]. Heilongjiang foreign trade and economic cooperation, 2009 (7):66-68

[7] He Xuejun. The analysis of the development trend of Chinese pharmaceutical logistics [J]. value engineering, 2012:20-21 
[8] Fan Lili. Grey relational grade evaluation method of enterprise core competitiveness [J]. Journal of management, 2011, 8 (12): 1859-1865

[9] Dai Junliang. Study on enterprise competitive strategy evaluation and application of core competence [J]. Journal of Central University of Finance and Economics, 2008 (1): 43-48

[10] Wang Liang. Strategies for enhancing the competitiveness of pharmaceutical logistics enterprises [J]. cooperation in economics and technology, 2014,11 (47): 84-85
[11] Yang xinyi. Discussion on the development of pharmaceutical e-commerce in the Internet + era [J]. Medical research, 2016(35):60-62

[12] Wang ping. The operational status and existing problems of pharmaceutical logistics [J]. China medical guide, 2014,11(23):132-135

[13] Xu Yang hua. Research review and foresight of core competitiveness of enterprises [J]. East China economic management, 2005,19(11):29-35 